\title{
Solid State Characterization of Olmesartan medoximil Solid Dispersion and in-silico Formulation Design using Quality by Design Techniques Engendered by Definitive Screening Design
}

\author{
Shabari Girinath Kala ${ }^{1 * *}$, Santhivardhan Chinni ${ }^{2}$ \\ 'Research Scholar, Department of Pharmaceutical Sciences, Jawaharlal Nehru Technological University, Ananthapuramu, Andhra Pradesh, INDIA. \\ ${ }^{2}$ Associate Professor, Raghavendra Institute of Pharmaceutical Education and Research (RIPER), Anantapuramu, Andhra Pradesh, INDIA.
}

\begin{abstract}
Objectives: Olmesartan medoxomil (OM) is employed for treating patients who are intolerant of ACE inhibitors. The challenge to the researchers is because of its poor oral bioavailability and poor solubility. The approach for this problem is to use a hydrophilic carrier in formulation of oro-dispersible tablet (ODT) which presents a suitable way to improve the bioavailability by using quality by design $(\mathrm{ObD})$ techniques with design of experiments (DoE) using definitive screening design (DSD) which produce a robust and rugged formulation. Methods: The focus of the research was to formulate OM/PVP solid dispersion (SD) and formulation of an Oro dispersible tablet (ODT) by $\mathrm{QbD}$ techniques. The main focus of this research is to provide a rugged and robust formulation using $\mathrm{QbD}$ concept with the application of Definitive screening design for optimization. Results: The dissolution studies of OM/PVP K30 1:1\% w/w showed full release within 30 min which may be attributed due to the hydrogen bond formation between OM and PVP K30 in the FTIR spectra which enhanced the solubility. The disintegration and dissolution results were found to be satisfactory and meeting the desired quality target product profile (QTPP). Conclusion: The
\end{abstract}

present research highlights a thorough understanding of the dosage form development with the knowledge of the critical risks involved in formulation to have an impact on critical quality attributes (CQAs). The critical material attributes (CMAs) were refined by DoE using definitive screening design (DSD) to develop design space.

Key words: Critical material attributes (CMAs), Critical quality attributes (CQAs), Definitive screening design (DSD), Quality by design (QbD), Design of experiments (DoE).

Correspondence

Mr. Shabari Girinath Kala

Research Scholar, Department of Pharmaceutical Sciences, Jawaharlal Nehru Technological University, Ananthapuramu-515002, Andhra Pradesh, INDIA.

Phone: +91 040-9490120635

Email: shabari.niper@gmail.com

DOI: 10.5530/jyp.2021.13.11

\section{INTRODUCTION}

Olmesartan medoxomil (OM) used an antagonist of angiotensin II receptor for treating high blood pressure. OM administered as a prodrug, has few drawbacks that it is completely de-esterified to Olmesartan as an active metabolite. ${ }^{1}$ It acts by inhibiting the vasoconstrictor effects. ${ }^{2}$ The usual recommended initial dose is $20 \mathrm{mg}$ per day. ${ }^{3}$ Several preparations containing Olmesartan medoxomil and other antihypertensives are available in the market. ${ }^{4}$ To overcome the drawbacks of low oral bioavailability the researcher aims to improve the dissolution of least water-soluble drugs by solubilization using some vehicle, reduction of particle size, solid dispersion and salt formation. The drugs polymorphism can be changed from crystalline to an amorphous state in solid dispersion system thus improving the solubility ${ }^{5}$ and also particle size reduction done for improved wettability. ${ }^{6}$ The drug solubility is also improved by the presence of the carrier which creates a microenvironment. ${ }^{7}$ Polyvinylpyrrolidone (PVP) is a synthetic high molecular weight polymer having linear groups of monomers of 1-vinyl2-pyrrolidone exhibiting least toxicity with more hydrophilic property, physiological tolerance and enhances drug release and bioavailability ${ }^{8}$ as it is having universal solubility in hydrophilic and hydroobic solvents. ${ }^{8}$

Taking all the above into account, the aim of this research work is to prepare solid dispersions of OM in PVP K30 using solvent evaporation technique and formulate it into an Oro Dispersible Tablet with QbD technology by using the design of experiments.

\section{MATERIALS AND METHODS}

\section{Materials}

Olmesartan medoxomil, an active pharmaceutical ingredient, was obtained as gift sample from MSN Organics Pvt. Ltd., Hyderabad, India. PVP K30, Crosspovidone and starch purchased from Ascot Pharmachem Pvt. Ltd., Vadodara, India, Mannitol, Magnesium stearate and Aspartame purchased from Sigma Aldrich, Mumbai, India.

\section{Methods}

\section{Preparation of Olmesartan medoxomil solid dispersion}

Solid dispersions with mass ratio of OM to PVP K30 ranging from 1:0.5 to $1: 1.5$ were formulated by solvent evaporation method. ${ }^{9}$ In brief, PVP K30 was dissolved in ethanol, followed by addition of OM. Ultrasonication at room temperature was done for about an hour to dissolve the drug completely ${ }^{10}$ and the remaining solvent was subjected to reduced pressure for evaporation. The resulting product was dried for $24 \mathrm{~h}$ at room temperature over anhydrous $\mathrm{CaCl}_{2}$ desiccators in vacuum. The dried product was then pulverized and subjected through BSS 60\# and stored in a desiccators ${ }^{8,11}$ and further evaluation done using Fourier transform infrared spectroscopy (FTIR Systronics, Ahmedabad, India).

\section{Formulation of tablets with SD technology}

Listed ingredients were weighed in required quantity and passed through suitable mesh. Binder solution was prepared by dissolving in starch in 
required amount of hot water and it is added to the drug-ingredient mixture to get uniform mass and passed through the suitable sieve and dried for $4 \mathrm{hrs}$ in hot air oven at $45^{\circ} \mathrm{C}$. Lubricants were added to the dried granules and micrometric properties were analysed and compressed with $5.2 \mathrm{~mm}$ concave punch. Formulated product was evaluated for physicochemical parameters.

\section{Optimization of ODT parameters as per enhanced QBD}

Optimization of the formulation using design of experiments with $\mathrm{QbD}$ approach, ${ }^{12} \mathrm{QRM}^{13}$ and knowledge management ${ }^{14}$ gives a robust formulation throughout the life cycle of the product.

\section{Identification of CMA and CQA with justification}

CQAs are linked with the drug substance, drug product and excipients. ${ }^{15}$ Relevant CQAs were identified based on the experience and prioritized through QRM and experimentation was done to assess the extent of variation of CMA's impact on the CQA.

Risk assessment of material attributes by QRM is a scientific approach that help in identifying CMA and CPP which show effect on product CQAs along with justification (Table 1). Experimentation was done using Design of Experiments (DoE) software to refine the list further to

Table 1: Initial Risk Assessment of the Material Attributes with Justification.

\begin{tabular}{|c|c|c|c|}
\hline CMA & CQA & Target & Justification \\
\hline \multirow[t]{2}{*}{ Carrier } & 1. Dissolution & $\begin{array}{l}\text { NLT } 90 \% \text { at } \\
30 \mathrm{~min}\end{array}$ & $\begin{array}{l}\text { 1. Carrier amount has } \\
\text { direct impact on formation } \\
\text { of solid dispersion thus } \\
\text { inturn effects dissolution. } \\
\text { Thus, the risk is medium. }\end{array}$ \\
\hline & 2.Disintegration & $\begin{array}{l}\text { Less than } \\
30 \mathrm{sec}\end{array}$ & $\begin{array}{l}\text { 2. Carrier amount has } \\
\text { negligible direct affect on } \\
\text { tablet disintegration time. } \\
\text { Therefore, risk is low }\end{array}$ \\
\hline \multirow[t]{2}{*}{ Binder } & 1.Dissolution & $\begin{array}{l}\text { NLT } 90 \% \text { at } \\
30 \mathrm{~min}\end{array}$ & $\begin{array}{l}\text { 1. Binder concentration } \\
\text { has direct affect on } \\
\text { dissolution. Therefore risk } \\
\text { is high. }\end{array}$ \\
\hline & 2.Disintegration & $\begin{array}{l}\text { Less than } \\
30 \mathrm{sec}\end{array}$ & $\begin{array}{l}\text { 2. Binder concentration } \\
\text { can affect the time of } \\
\text { disintegration of tablet. } \\
\text { Therefore risk is high }\end{array}$ \\
\hline \multirow[t]{2}{*}{ Disintegrant } & 1.Dissolution & $\begin{array}{l}\text { NLT } 90 \% \text { at } \\
30 \mathrm{~min}\end{array}$ & $\begin{array}{l}\text { 1. Excess/Low level of } \\
\text { disintegrant may affect the } \\
\text { dissolution of tablet. Thus, } \\
\text { the risk is high }\end{array}$ \\
\hline & 2.Disintegration & $\begin{array}{l}\text { Less than } \\
30 \mathrm{sec}\end{array}$ & $\begin{array}{l}\text { 2. Excess/Low level } \\
\text { of disintegrant level } \\
\text { may affect the tablet to } \\
\text { disintegrate fastly/slowly. } \\
\text { Therefore risk is high }\end{array}$ \\
\hline \multirow[t]{2}{*}{$\begin{array}{c}\text { Magnesium } \\
\text { Stearate }\end{array}$} & 1.Dissolution & $\begin{array}{l}\text { NLT } 90 \% \text { at } \\
30 \mathrm{~min}\end{array}$ & $\begin{array}{l}\text { 1. Higher lubrication } \\
\text { because of higher lubricant } \\
\text { may slow dissolution. } \\
\text { Therefore, risk is medium. }\end{array}$ \\
\hline & 2.Disintegration & $\begin{array}{l}\text { Less than } \\
30 \mathrm{sec}\end{array}$ & $\begin{array}{l}\text { 2. Magnesium stearate } \\
\text { exhibits best lubrication } \\
\text { properties, however it } \\
\text { has less likely impact } \\
\text { on disintegration time. } \\
\text { Therefore risk is low. }\end{array}$ \\
\hline
\end{tabular}

evaluate the importance of individual variables and interactions to gain a higher degree of understanding. ${ }^{16}$

\section{Optimization of material attributes and development of design space}

Based on Initial Risk Matrix Analysis (IRMA), formulation understanding experiments viz DoE were implemented for the formulation. The effect of every independent CMAs on dependent CQAs (e.g. disintegration and dissolution) were analysed for establishment of Design space (DS) through timely evaluation of CQA which were modelled out with the target of achieving quality product. Definitive screening design (DSD) was used (Table 2) for optimization procedure for establishment of DS, because the design offers three levels and provides main effects estimation which were unbiased through any second order effects and requires only one trial greater than twice as many trials as there are factors and eliminates confounding effects on any pair of second order models thus favouring optimization of material attributes to achieve desired CQA. DSD was done using Design-Expert ${ }^{\star}$ software (Version 12, Stat-Ease Inc., Minneapolis, MN). ${ }^{17}$ Depending on IRMA, DoE were implemented for formulaion having higher risk priorities. ${ }^{18}$

\section{RESULTS}

The present work was aimed to prepare ODT for Olmesartan medoxomil solid dispersion to increase bioavailability. Among the various approaches involved, ODT approach was selected as they are easy to fabricate and thereby enhancing the absorption of the drug. For this purpose, wet granulation technique was used with different excipients.

\section{Drug-carrier interaction studies}

FT-IR spectra helps in interpreting the interaction between the drug ad other materials as shown in (Figure 1A and 1B). The spectra of pure OM showed bands at $3398.91 \mathrm{~cm}^{-1}$ owing to $\mathrm{N}-\mathrm{H}$ stretch, at $1706.98 \mathrm{~cm}^{-1}$ owing to $\mathrm{C}=\mathrm{O}$ stretching, The spectra also showed bands at $1225.39 \mathrm{~cm}^{-1}$ owing to C-N bending. In the region, the $3398.91 \mathrm{~cm}^{-1} \mathrm{NH}$ stretching vibration peak of OM disappeared in the $\mathrm{SD}$. It seems that there is a formation of intermolecular hydrogen bond between - $\mathrm{NH}$ of $\mathrm{OM}$ and $-\mathrm{C}=\mathrm{O}$ of PVP. Thus, the appearance of characteristic absorption bands of $\mathrm{OM}$ and the solid dispersion containing $\mathrm{OM}$ showed no interaction between the $\mathrm{OM}$ and excipients.

\section{Formulation Development Study}

A Definitive Screening Design (DSD) with four factors and three levels were chosen to optimize varied response variables. The factors studied were decoded to allow for the ANOVA study. The relationship between factors and responses were elucidaed by using counter plots. The Figure $2 \mathrm{~A}$ indicates the ANOVA for Response Surface Quadratic for disintegration

\section{Table 2: DSD study to investigate CMA and CQA.}

\begin{tabular}{cccccc} 
& \multicolumn{2}{c}{ Factors: CMA } & & \multicolumn{3}{c}{ Levels } \\
\cline { 4 - 6 } & & & -1 & 0 & +1 \\
\hline A & Carrier & 10 & 20 & 30 \\
B & Disintegrant & 10 & 20 & 30 \\
C & Binder & & 1 & 2 & 3 \\
D & Lubricant & & 1 & 3 & 5 \\
\multicolumn{2}{|c}{} & Responses & Goal & \multicolumn{3}{c}{ Ranges Acceptable } \\
Y1 & Disintegration time & Range & \multicolumn{3}{c}{$20-30$} \\
Y2 & Dissolution 15 min & Range & \multicolumn{3}{c}{$60-80$} \\
Y3 & Dissolution 30 min & Range & \multicolumn{3}{c}{$80-100$} \\
\hline
\end{tabular}


was found to be significant $(P<0.05)$ indicating fitness of the choosen equation Sqrt (Disintegration) $=+4.89+0.6466 \mathrm{~A}-1.46 \mathrm{~B}+2.42 \mathrm{C}+1.54 \mathrm{~A}^{2}$ and Contour plot for disintegration indicates an interaction between the critical factors and response variables respectively. The $2 \mathrm{D}$ graph for disintegration indicates the effect of carrier and disintegrant on disintegration time. At high levels of disintegrant, the disintegration time decreases and carrier does not have much influece on disintegration time.

The Figure 2B indicates the ANOVA for Response Surface Quadratic for \% drug release profile at 15 mins (Q15) was found to be significant $(P<0.05)$ indicating fitness of the choosen equation dissolution at 15 $\min =+66.59+4.80 \mathrm{~A}-1.80 \mathrm{C}-5.88 \mathrm{~A}^{2}-5.88 \mathrm{C}^{2}$ and Contour plot for $\% \mathrm{drug}$ release profile at 15 mins (Q15) indicates an interaction between the critical factors and response variables respectively. The $2 \mathrm{D}$ graph for Q15 indicates that effect carrier and disintegrant on \%drug release at 15 minutes. As the carrier level increases from $10 \mathrm{mg}$ to $20 \mathrm{mg}$ dissolution increases and remains constant when the carrir level further increases. The Figure 2C indicates the ANOVA for Response Surface Quadratic for \% drug release profile at 30 mins (Q30) was found to be significant $(P<0.05)$ indicating fitness of the choosen equation dissolution at 30 $\min =+95.33+6.20 \mathrm{~A}+1.90 \mathrm{~B}-2.70 \mathrm{C}-3.13 \mathrm{AB}-10.13 \mathrm{~A}^{2}$ and Contour plot

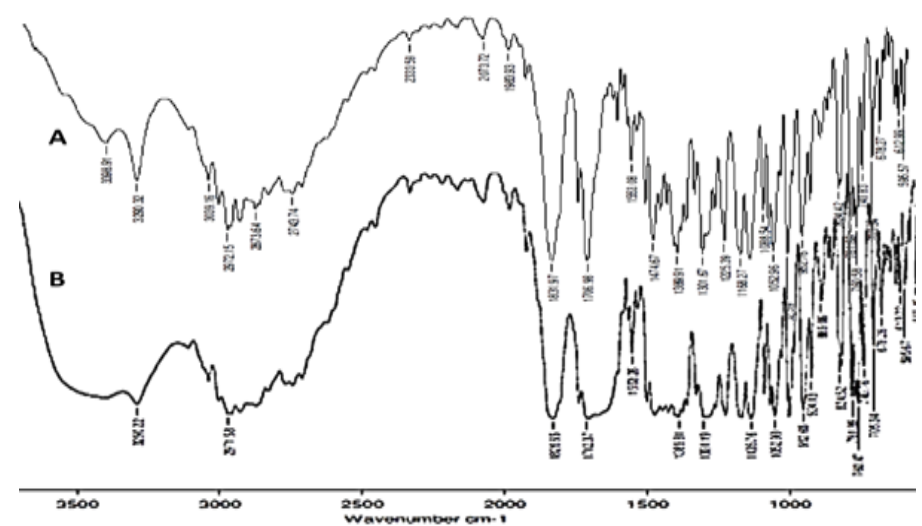

Figure 1: A. Fourier transform infrared spectra of Olmesartan medoxomil B. Spectra of FTIR showing peaks for solid dispersion of OM with PVP K30. for \% drug release profile at 30 mins (Q30) indicates an interaction between the critical factors and response variables respectively. The $2 \mathrm{D}$ graph for Q30 indicates that effect carrier and disintegrant on \%drug release at 30 minutes. As the carrier level increases from $10 \mathrm{mg}$ to $20 \mathrm{mg}$ dissolution increases and remains constant when the carrier level further increases. The dissolution \% slowly increases as the amount of disintegrant increases from $15 \mathrm{mg}$ to $20 \mathrm{mg}$. Disintegration and Dissolution (Q15, Q30. \% drug release at 15 and 30 minutes) were taken as response variables (CQAs) and the corresponding results were shown (Table 3).

The experimental results for disintegration and dissolution at $15 \mathrm{~min}$ and $30 \mathrm{~min}$ when compressed at hardness $8 \mathrm{kpa}$ and thickness $2.5 \mathrm{~mm}$
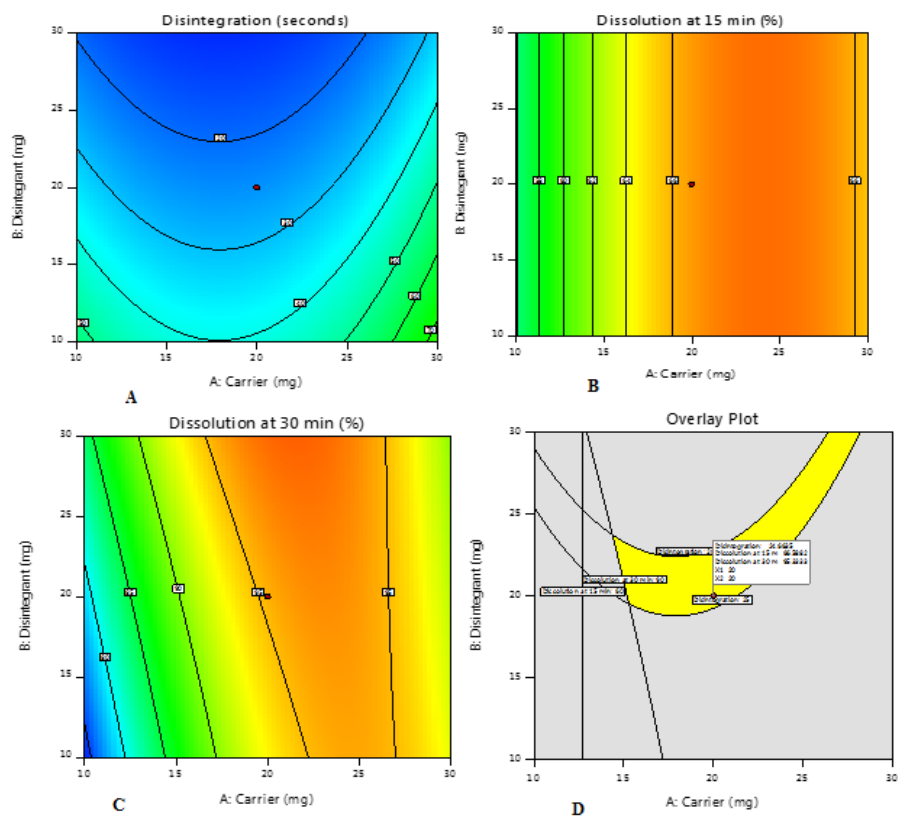

Figure 2: A. Effect on disintegration time due to carrier and disintegrant B. Effect on dissolution at 15 min due to carrier and disintegrant C. Effect on dissolution at $30 \mathrm{~min}$ due to carrier and disintegrant D. Overlay plot showing the Design Space.

Table 3: Experimental results to study carrier and excipients.

\begin{tabular}{|c|c|c|c|c|c|c|c|}
\hline \multirow[b]{2}{*}{ Run } & \multicolumn{3}{|c|}{ Factors } & \multicolumn{3}{|c|}{ Responses } & \multirow[b]{2}{*}{ Dissolution at $30 \mathrm{~min}$} \\
\hline & A:Carrier & B:Disintegrant & C:Binder & D:Lubricant & Disintegration & Dissolution at $15 \mathrm{~min}$ & \\
\hline & $\mathrm{mg}$ & $\mathrm{mg}$ & $\mathrm{mg}$ & $\mathrm{mg}$ & Seconds & $\%$ & $\%$ \\
\hline 1 & 30 & 30 & 3 & 1 & 68 & 58 & 86 \\
\hline 2 & 30 & 30 & 1 & 3 & 8 & 64 & 94 \\
\hline 3 & 30 & 10 & 3 & 5 & 127 & 58 & 89 \\
\hline 4 & 10 & 20 & 3 & 1 & 50 & 50 & 78 \\
\hline 5 & 10 & 30 & 1 & 1 & 7 & 56 & 88 \\
\hline 6 & 20 & 20 & 2 & 3 & 21 & 70 & 100 \\
\hline 7 & 10 & 30 & 2 & 5 & 12 & 55 & 82 \\
\hline 8 & 20 & 30 & 3 & 5 & 48 & 58 & 92 \\
\hline 9 & 10 & 10 & 3 & 3 & 97 & 47 & 73 \\
\hline 10 & 20 & 10 & 1 & 1 & 10 & 60 & 94 \\
\hline 11 & 30 & 20 & 1 & 5 & 21 & 61 & 95 \\
\hline 12 & 10 & 10 & 1 & 5 & 35 & 48 & 74 \\
\hline 13 & 30 & 10 & 2 & 1 & 72 & 63 & 93 \\
\hline
\end{tabular}


Table 4: Final optimized formulation.

\begin{tabular}{cc}
\hline Ingredients $(\mathrm{mg})$ & $\mathrm{mg} /$ tablet \\
\hline Intragranular Portion & 20 \\
Pure drug & 20 \\
PVP K30 (carrier) & 20 \\
Crosspovidone (disintegrant) & 34 \\
Mannitol (diluent) & 2 \\
Starch Rx 1500 (binder as paste) & 1 \\
Aspartame (sweetener) & \\
Extragranular Portion & 3 \\
Magnesium stearate (lubricant) & 100 \\
Total weight & \\
\hline
\end{tabular}

indicate that all weight variation, thickness, friability and hardness were within the permissible limits of USP.

Thus, a composition having desired level of excipients is mentioned (Table 4). The optimized formulation has bulk density $0.295 \mathrm{~g} / \mathrm{ml}$, angle of Repose $25^{\circ} .56$, Tapped Density $0.335 \mathrm{~g} / \mathrm{ml}$, Hausner's ratio 1.15 and Carr's index $11.94 \%$. The optimized formulation blend is compressed in to the tablets and quality control tests were done. The disintegration and dissolution results were found to be satisfactory and meeting the desired quality target product profile (QTPP).

\section{DISCUSSION}

The drug OM shows poor oral bioavailability due to its poor solubility which leads to reduced therapeutics efficacy. The thought-provoking aspect here is to enchance the bioavailabilty through the use of solid dispersion technique where a hydrophilic matrix polymer in the form of solvent was mixed with hydrophobic rug making it to form a dispersion. ${ }^{19}$ Ethylalcohol is used as a solvent to solubilize the drug ${ }^{20}$ and it can be removed easily through evaporation. Ultrasonication was performed to simulate the homogenization effect and to disolve the drug completely ${ }^{10}$ because of the reduction of the particle size and increase in surface area. In the formed solid dispersion, the drug can be present as molecularly dispersed, ${ }^{19,20}$ amorphous ${ }^{19}$ or microcrystal state ${ }^{21}$ with high energy. Once the solid dispersion was prepared, it was analysed to assess the physical sate of the drug. It was found that the drug was molecularly dispersed in the PVP when it was used in the ratio of 1:1 when compared with the literature results in which 1:6 ratio of drug and PEG-4000 was used. ${ }^{22}$ The amount of moleculary dispersed drug depends $n$ the ratio of the drug and the polymer. ${ }^{23}$ The solid dispersion formed was characterized using FTIR which shows no interaction between drug and polymer and formation of intermolecular hydrogen bond between $-\mathrm{NH}$ of $\mathrm{OM}$ and $-\mathrm{C}=\mathrm{O}$ of $\mathrm{PVP}^{24}$ during the solvent evaporation process confirms the molecular dispersion of drug into the polymer matrix and further the formed SD used as an active ingredient for the formulation of tablets. ${ }^{25}$ These findings are important, in the light of $\mathrm{QbD}$ concept in the pharmaceutical formulation development since $\mathrm{QbD}$ requires knowledge of the influence of formulation components (material attributes) on the final product properties and identification of interactions in order to select the optimal formulation. Definitive screening design was chosen to optimize the formulation with four factors viz carrier (X1), disintegrant (X2), binder (X3) and lubricant (X4) and three responses viz disintegration (Y1), dissolution at $15 \mathrm{~min}$ (Y2) and dissolution (Y3). Dissolution medium used contains $\mathrm{pH} 6.8$ phosphate buffer in type 2 apparatus operated at a speed of $50 \mathrm{rpm}$ for $30 \mathrm{~min}$ and analysed at $257 \mathrm{~nm}$ as per USP. One of the main goals in SD processing is to achieve an improvement in the dissolution rate of $\mathrm{OM}$ and the results obtained are comparitively equivalent with the literature reports in tems of drug release of $\mathrm{OM}$ with polaxmer $407,{ }^{9}$ faster than $\mathrm{OM}$ with cyclodextrin. ${ }^{26}$ Faster than $\mathrm{OM}$ with VA64 ${ }^{27}$ and faster than OM with soluplus. ${ }^{27}$ Dissolution studies revealed that the formulations are in accordance to the USP requirements for OM immediate release tablets. The $2 \mathrm{D}$ counter graph indicates that inclusion of PVP K30 in the mixture influences positivey the amount of OM released (\%) after 15 min and $30 \mathrm{~min}$, but only up to a certain amount, which corresponds to approximately $1: 1$ ratio of OM to PVP K30 and were confirmed by the release from formulation labelled as run 6 (containing approximately 1:1 ratio of both OM and PVP K30), which had the fastest onset.

On the basis of the obtained results, it is clear that immediate release solid dispersions of OM can be successfully prepared using the solvent evaporation technique. Regardless of their composition, all critical material attributes display an improvement in the release rate and the percentage of OM released, compared to the pure OM which showed $25 \%$ release in $30 \mathrm{~min}$. The study demonstrated that interactions between the mixture components (SD and excipients), or the quadratic effects of the components, play a significant role in overall influence on the OM release rate. After analysing the data obtained through ANOVA using the final equation, the desired goal for each CMA and CQA were chosen in Design Expert software. The goal selection starts at initial point and goes to a maximum where it was required to select a region where requirements meet the CQA. Graphical optimization showed the area of feasible response values in yellow colour. The gray shaded region indicates that the optimizaton criteria did not met as represented in Figure 2D. The yellow region constituted a possible design space for robust and rugged Formulation. From the results obtained through design space, the risk assessment of the material attributes was updated as low for all the CQA. Thus the study design successfully predicted values of independent variables for optimization of the dosage form. All the experimental values were in close agreement with the predicted vlues indicating goodness of fit for the model. ${ }^{21}$ Application of DSD has enabled the quantitative description of the relations between mixture components. These findings can serve as a foundation for the optimization of the future OM immediate release products.

\section{CONCLUSION}

The possible enhancement of dissolution rate was due to solid dispersion containing 1:1 mass ratio of OM:PVP K30. The appearance of hydrogen bonding between the $>\mathrm{NH}$ of $\mathrm{OM}$ and $-\mathrm{C}=\mathrm{O}$ of PVP $\mathrm{K} 30$ in $\mathrm{SD}$ characterised by FTIR leads to decrease in crystallinity and the primary reason for the marked increase of dissolution rate. The results showed that OM-PVP K30 SD formulated using solvent evaporation served as a means of increasing OM dissolution rates. The results of QRM study of ODT formulation proved that statistical tools of QbD helped in achieving the quality product throughout the lifecycle.

\section{ACKNOWLEDGEMENT}

The authors are immensely thankful to M/s. MSN Organics Pvt Ltd., Hyderabad, India for the gift sample of Olmesartan medoxomil (API).

\section{CONFLICT OF INTEREST}

The authors declare no conflict of interest

\section{ABBREVIATIONS}

CMA: Critical material attributes; CQA: Critical Quality Attributes; QTPP: Quality Target Product Profile; ODT: Oro dispersible tablet; DSD: Definitive Screening Design; FTIR: Fourier Transform Infrared 
Spectroscopy; QbD: Quality by Design; PVP: Polyvinylpyrrolidone; DoE: Design of Experiments; QRM: Quality Risk Management; SD: Solid Dispersion; ANOVA: Analysis of Variance.

\section{REFERENCES}

1. Mire DE, Silfani TN, Pugsley MK. A review of the structural and functional features of olmesartan medoxomil, an angiotensin receptor blocker. J Cardiovasc Pharmacol. 2005;46(5):585-93. doi: 10.1097/01.fjc.0000180902.78230.fd.

2. Norwood D, Branch E, Smith B, Honeywell M. Olmesartan medoxomil for hypertension: A clinical review. Drug Forecast. 2002;27(12):611-8.

3. Bergmann KV, Laeis P, Püchler K, Sudhop T, Schwocho LR, Gonzalez L. Olmesartan medoxomil: Influence of age, renal and hepatic function on the pharmacokinetics of olmesartan medoxomil. J Hypertens Suppl. 2001;19(1):S33-40. doi: 10.1097/00004872-200106001-00005.

4. Ruilope L, Schaefer A. The fixed-dose combination of olmesartan/amlodipine was superior in central aortic blood pressure reduction compared with perindopril/amlodipine: A randomized, double-blind trial in patients with hypertension. Adv Ther. 2013:30(12):1086-99. doi: 10.1007/s12325-013-0076-6.

5. Tiwari R, Tiwari G, Srivastava B, Rai AK. Solid dispersions: An overview to modify bioavailability of poorly water soluble drugs. Int J Pharmtech Res. 2009;1(4):1338-49.

6. Vasconcelos T, Sarmento B, Costa P. Solid dispersions as strategy to improve oral bioavailability of poor water soluble drugs. Drug Discov Today. 2007;12(2324):1068-75. doi: 10.1016/j.drudis.2007.09.005.

7. Mukharya A, Patel PU, Shenoy D, Chaudhary S. Quality risk management of top spray fluidized bed process for antihypertensive drug formulation with control strategy engendered by Box-behnken experimental design space. Int J Pharm Investig. 2013;3(1):15. doi: 10.4103/2230-973X.108960

8. Mukharya A, Chaudhary S, Mansuri N, Misra AK. Solid-state characterization of lacidipine/PVP K29/32 solid dispersion primed by solvent co-evaporation. Int J Pharm Investig. 2012;2(2):90.

9. Mali RK. Fast disintegrating tablets of olmesartan medoxomil using solid dispersion technique. Asian J Pharm. 2017;11(02). doi: 10.22377/ajp. v11i02.1299.

10. Balakrishnaiah M, Gupta VRM. Enhancement of solubility and dissolution rate of olmesartan medoxomil by solvent evaporation technique. Der Pharmacia Lettre. 2016;8(7):94-104.

11. Kamble $R$, Palve $P$, Mehta P. Preparation and evaluation of amorphous olmesartan medoxomil with porous silica microparticles using spray-drying technique. CA Cancer J Clin. 2014;4(4):444-50.

12. Mishra SM, Rohera BD. An integrated, quality by design (QbD) approach for design, development and optimization of orally disintegrating tablet formulation of carbamazepine. Pharm Dev Technol. 2017;22(7):889-903. doi: 10.1080/10837450.2016.1199566.

13. Cunha S, Costa CP, Moreira JN, Lobo JS, Silva AC. Using the quality by design $(\mathrm{QbD})$ approach to optimize formulations of lipid nanoparticles and nanoemulsions: A review. Nanomedicine. 2020;102206. doi: 10.1016/j. nano.2020.102206.

14. Guideline IHT. Pharmaceutical quality system q10. Current Step. 2008;4.

15. Lionberger RA, Lee SL, Lee L, Raw A, Lawrence XY. Quality by design: Concepts for ANDAs. AAPS J. 2008;10(2):268-76. doi: 10.1208/s12248-008-9026-7.

16. Maxwell SE, Delaney HD, Kelley K. Designing experiments and analyzing data: A model comparison perspective: Routledge. 2017.

17. Jones B, Nachtsheim CJ. A class of three-level designs for definitive screening in the presence of second-order effects. J Food Qual Technol. 2011;43(1):1-15. doi: 10.1080/00224065.2011.11917841.

18. Lawrence $X Y$. Pharmaceutical quality by design: Product and process development, understanding and control. Pharm Res. 2008;25(4):781-91. doi: 10.1007/s11095-007-9511-1.

19. Goldberg AH, Gibaldi M, Kanig JL. Increasing dissolution rates and gastrointestinal absorption of drugs via solid solutions and eutectic mixtures I: Theoretical considerations and discussion of the literature. J Pharm Sci. 1965;54(8):1145-48.

20. Serajuddin AT. Solid dispersion of poorly water-soluble drugs: Early promises subsequent problems and recent breakthroughs. J Pharm Sci. 1999;88(10):105866.

21. Sekiguchi K, Obi N. Studies on Absorption of Eutectic Mixture. I. A Comparison of the Behavior of Eutectic Mixture of Sulfathiazole and that of Ordinary Sulfathiazole in Man. Chem Pharm Bull. 1961;9(11):866-72.

22. Khan A, labal Z, Shah Y, Ahmad L, Ullah Z, Ullah A. Enhancement of dissolution rate of class II drugs (Hydrochlorothiazide): A comparative study of the two novel approaches; solid dispersion and liqui-solid techniques. Saudi Pharm J. 2015;23(6):650-7.

23. Djuris J, Nikolakakis I, lbric $S$, Djuric $Z$, Kachrimanis $K$. Preparation of carbamazepine-oluplus ${ }^{\circledR}$ solid dispersions by hot-melt extrusion, and prediction of drug-polymer miscibility by thermodynamic model fitting. Eur $\mathrm{J}$ Pharm Biopharm. 2013;84(1):228-37.

24. Wu JX, Yang M, DenBerg FV, Pajander J, Rades T, Rantanen J. Influence of solvent evaporation rate and formulation factors on solid dispersion physical stability. Eur J Pharm Sci. 2011;44(5):610-20.

25. Sammour OA, Hammad MA, Megrab NA, Zidan AS. Formulation and optimization of mouth dissolve tablets containing rofecoxib solid dispersion. AAPS Pharm Sci Tech. 2006;7(2):E167-75.

26. Zhang $\mathrm{Q}$, Ren W, Dushkin AV, Su W. Preparation, characterization, in vitro and in vivo studies of olmesartan medoxomil in a ternary solid dispersion with $\mathrm{N}$-methyl-D-glucamine and hydroxypropyl- $\beta$-cyclodextrin. J Drug Deliv Sci Technol. 2020;56:101546

27. Jadhav P, Gokarna $V$, Deshpande $V$, Vavia P. Bioavailability enhancement of olmesartan medoxoil using hot-melt extrusion: In-silico, in-vitro, and in-vivo evaluation. AAPS Pharm SciTech. 2020;on. AAPS PharmSciTech. 2020;21(7):1 17. doi: $10.1208 / \mathrm{s} 12249-020-01780-3$.

Article History: Submission Date : 20-10-2020; Revised Date : 06-12-2020; Acceptance Date : 01-02-2021

Cite this article: Kala SG, Chinni S. Solid State Characterization of Olmesartan medoximil Solid Dispersion and in-silico Formulation Design using Quality by Design Techniques Engendered by Definitive Screening Design. JYoung Pharm. 2021;13(1):49-53. 